\title{
Tooth development standards for South Australia
}

\author{
CJ McKenna, * H James, * JA Taylor,* GC Townsend†
}

\begin{abstract}
Background: Chronological age, as recorded by registration of birth date, is referred to throughout an individual's life. This information is relevant in medical and dental practice for evaluating developmental progress, for educational purposes, and in legal matters, particularly in the application of criminal law. The absence of birth date information raises particular concerns, and estimates of chronological age are often required. Standards of dental maturation may be used to estimate age, but they have been shown to be gender and population sensitive.

Methods: The revised Demirjian ${ }^{1}$ system of dental age estimation was applied to a sample of 615 South Australian children in order to assess its accuracy. Results: The results of our study have shown that the Demirjian system is of limited accuracy when used to estimate the age of South Australian children. Conclusions: Generation of new standard curves, specific to the Australian population, is indicated.

Key words: Age determination, dental development, forensic odontology, South Australia.
\end{abstract}

(Accepted for publication 1 October 2001.)

\section{INTRODUCTION}

It is accepted generally that somatic development is related to chronological age and, as a result, measurements of somatic maturity, for example bone age, menarche and height, have been used to estimate chronological age in the absence of accurate age data. ${ }^{2}$ Tooth development shows less variability than other developmental features and also low variability in relation to chronological age. ${ }^{3}$ For example, Lewis ${ }^{4}$ compared tooth formation with other maturational events, such as appearance of bone ossification centres, and found the maturational events of tooth formation and apical closure to be no more, and often less, variable than the other developmental events studied. In addition, Hotz ${ }^{5}$ observed a greater degree of association between dental age and chronological age than between dental age and skeletal age.

\footnotetext{
*Forensic Odontology Unit, Faculty of Health Sciences, The University of Adelaide.

†Dental School, Faculty of Health Sciences, The University of Adelaide.
}

The continuous patterns of tooth development can be observed on a longitudinal series of radiographs and various mineralization stages have been described. ${ }^{6-10} \mathrm{~A}$ number of methods have been proposed to determine dental age, ${ }^{11-13}$ but the system developed by Demirjian ${ }^{1}$ has gained wide acceptance.

Various workers have noted that, during the earlier stages, tooth development in males and females coincides closely. However, during later developmental stages, particularly root formation, a notable divergence between the sexes arises; with females being advanced when compared with males. ${ }^{14-15}$ In addition, studies of both skeletal and dental maturity from different populations have confirmed that interpopulation variation exists. ${ }^{16-19}$ It has been recommended frequently that standards appropriate for different populations, that make allowance for sexual dimorphism, are required..$^{20-21}$

Therefore, the aim of this study was to generate dental maturity scores for a population of South Australian children, using the revised system of Demirjian. ${ }^{1}$ Ages estimated from these scores were compared with the chronological ages of the subjects, to determine if the system provides accurate results that could be used for South Australian children; or whether new population-specific standards needed to be generated.

\section{MATERIALS AND METHODS}

The dental age of each subject was calculated by scoring teeth in the left mandibular quadrant. For any subject with an absent left permanent mandibular tooth, with the exception of third molars $(n=3)$, the equivalent tooth on the subject's right was used.

\section{Sample selection}

The data used in this study were obtained from copies of orthopantomographs (OPG) required for clinical purposes for a sample of 615 South Australian children, 288 males and 327 females, between 4.9 and 16.9 years of age. The subjects were children who attended various school dental clinics of the South Australian Dental Service, the Orthodontic Clinic, Adelaide Dental Hospital and private orthodontic practices in the metropolitan area of Adelaide. 
Table 1. Distribution of sample

\begin{tabular}{lccc}
\hline Group (years) & Male $(\mathrm{No})$ & Female $(\mathrm{No})$ & Total $(\mathrm{No})$ \\
\hline $4.9-6.9$ & 9 & 11 & 20 \\
$7.0-8.9$ & 80 & 83 & 163 \\
$9.0-10.9$ & 89 & 98 & 187 \\
$11.0-12.9$ & 49 & 54 & 103 \\
$13.0-14.9$ & 31 & 41 & 72 \\
$15.0-16.9$ & 30 & 40 & 70 \\
\hline & 288 & 327 & 615 \\
\hline
\end{tabular}

The sample was arranged in two-yearly intervals ranging from 4.9-6.9 to 15-16.9 years. In order to facilitate calculation and statistical analysis the chronological ages were converted to years and months, where months were determined as a fraction of 12 months. For example 10 years and 10 months was expressed as 10.8 years.

The parent or guardian of each subject was required to complete a brief questionnaire. Included with the questionnaire was an information sheet providing details about the study. Completed questionnaires included signed consent of a parent or guardian, details of any medical condition, date of birth and country of birth of the subject, and also country of birth for the subject's parents and grandparents.

Subjects excluded from the sample included those where consent and/or full details were not obtained or where the quality of the radiographic image was deemed insufficient. Also excluded from the study were subjects with known medical conditions.

\section{Chronological age}

Chronological age (CA) was determined from the date of birth, as indicated in the patient's details, and recorded as years and months. In males, CA ranged from 5.1 to 16.7 years, in females the range was 4.9 to 16.9 years.

\section{Estimated dental age}

Two observers independently assessed the stages of mineralization of the seven left mandibular permanent teeth using the eight stages of development identified and described by Demirjian ${ }^{11}$ and the revised scores published by Demirjian. ${ }^{1}$ Differences between the two observers were checked using a $t$ test for paired samples to check for systematic errors. The mean of the paired differences was small for both males and females (males 0.058 years; females 0.054 years) but still significant at $p<0.05$. Calculation of Dahlberg statistics ${ }^{22}$ to show the magnitude of the random error yielded a value of 0.12 years for both males and females.

The dental maturity scores were converted to dental ages by reference to magnified prints of the median curves provided by Demirjian. ${ }^{1}$ The dental ages were interpreted from the median curves in 0.1 year steps. The score corresponding to the 50th percentile was taken as estimated dental age (EDA).

\section{Country of birth}

The country of birth was recorded for each subject and also the country of birth of each subject's parents and grandparents. The countries of birth relating to each subject were grouped into one of 22 categories corresponding to modified Standard Australian Classification of Countries. ${ }^{23}$

\section{Statistical analysis}

Data were analysed using the SPSS ${ }^{x}$ for MacIntosh computer package. Estimated dental age was compared to CA, with the null hypothesis that EDA would not differ from CA. Assessment was also made of the influence of gender and ethnic origin. Parametric and non-parametric tests were used to determine the degree to which collected data were consistent with the hypotheses. Statistical significance was set at the 5 per cent probability level.

\section{RESULTS}

\section{Sample distribution}

The sample size was 615 , which was divided for convenience into six age groups, in intervals of two years (Table 1). Since OPGs were copied and scored only for children who required them for clinical purposes, numbers in younger age groups were limited.

\section{Comparison of chronological age and estimated dental age}

Histograms were constructed to show the percentage of cases where EDA was greater than, equal to and less than CA. A threshold is noted at the 15 year stage,

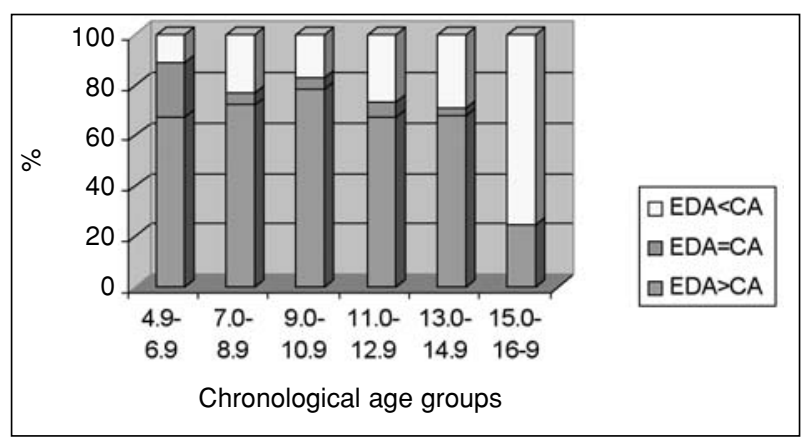

Fig 1a. Estimated vs chronological age: males.

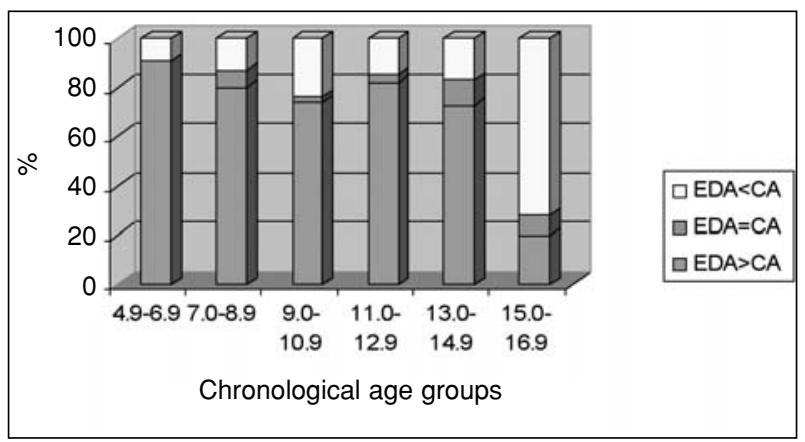

Fig 1b. Estimated vs chronological age: females.

Australian Dental Journal 2002;47:3. 
Table 2. Estimated dental age vs chronological age

\begin{tabular}{lcc}
\hline & Males & Females \\
\hline EDA $>$ CA & 196 & 230 \\
EDA=CA & 15 & 17 \\
EDA<CA & 77 & 80 \\
\hline Total & 288 & 327 \\
\hline
\end{tabular}

$\mathrm{p}<0.05$.

$\mathrm{X}^{2}=0.0028$ ( 2 degrees of freedom).

when the percentage of cases where EDA exceeds CA changes from approximately 70 to 25 per cent in males, and 80 to 20 per cent in females (Fig 1a, 1b).

Estimated dental age was compared with CA using the Wilcoxon matched-pairs signed-ranks test (Table 2), with the result that for both males and females EDA was greater than CA significantly more often than expected due to chance $(\mathrm{p}<0.05)$.

The ranges, means and standard deviations of the differences between EDA and CA were computed for each age group (Table 3 ). The greatest mean difference was 1.06 years, for females aged 11-12.9 years. Estimated dental age exceeded CA by 0.46 years on average in males under 15 years, but EDA was less than CA by 0.49 years on average in males over 15 years. Estimated dental age exceeded CA by 0.71 years on average in females under 15 years, but EDA was less than CA by 0.46 years on average in females over 15 years. All groups demonstrated large standard deviations.

The percentage of cases where EDA fell within $\mathrm{CA} \pm 0.5$ years was calculated for each age group. Overall, in only 34.7 per cent of males and 39.6 per cent of females was EDA within the range $\mathrm{CA} \pm 0.5$. For the different age categories, the highest percentage was 55 per cent for males 4.9-6.9 years, and the lowest 9.7 per cent for males 13-14.9 years (Fig 2).

\section{Sexual dimorphism}

Mean values and variances for EDA data were compared between males and females for each of the two-year age groups to determine if there was a statistical significance between the timing of male and female tooth development (Table 3). In the lower age groups, there was no statistical significance between genders. However, within the 11-12.9 year group there

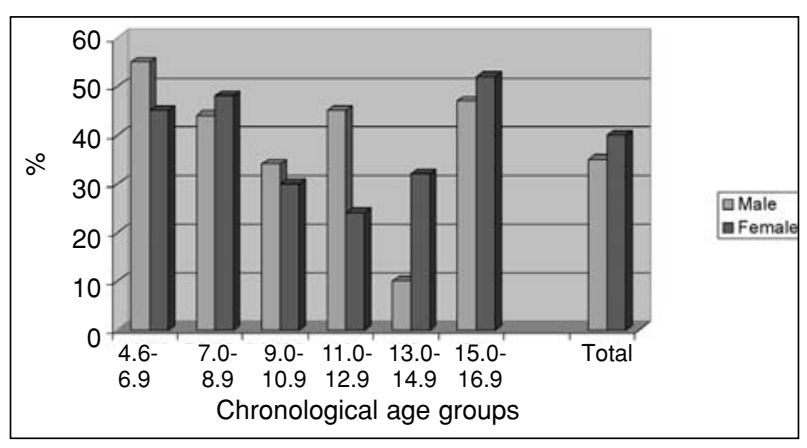

Fig 2. $\% \mathrm{EDA}=\mathrm{CA} \pm 0.5$ year

was a significant difference between sexes for EDA. In the 13-14.9 age group, there was a significant difference in the variance, but no significant difference in the mean. In the 15-16.9 age group, there was again significant difference in the variance of EDA data between males and females, but no difference in the mean value was evident.

The influence of gender on the difference between EDA and CA was further investigated using chi-square analysis. The distribution of subjects falling into three groups, $\mathrm{EDA}>\mathrm{CA}, \mathrm{EDA}=\mathrm{CA}, \mathrm{EDA}<\mathrm{CA}$ was compared between males and females. The results are summarized in Table 4. No significant association between grouping and sex was noted $(\mathrm{p}>0.05)$.

\section{Ethnic influence}

The data obtained for the country of birth were grouped in the categories: country of birth of subject; country of birth of mother; country of birth of father. Table 5 provides data for the distribution of groupings in Australian born and non-Australian born. No significant association was found $(p>0.05)$. For the subset of Australian-born children ( $\mathrm{N}=553)$, no statistical significance was shown when comparing Australian born vs non-Australian born parents.

The country of birth of child and parents was examined for the sub-sample of subjects where the difference between EDA and CA was greater than 2.5 years. Five males and 10 females had a chronological age differing from the estimated age by more than 2.5 years. Three of the males and four of the females were born in Australia, of Australian parents.

Table 3. Differences between EDA and CA (years)

\begin{tabular}{|c|c|c|c|c|c|c|}
\hline \multirow[b]{2}{*}{ Group } & \multicolumn{3}{|c|}{ Males } & \multicolumn{3}{|c|}{ Females } \\
\hline & Range & Mean & SD & Range & Mean & $\mathrm{SD}$ \\
\hline $4.9-6.9$ & -0.5 to 1.0 & 0.36 & 0.47 & -0.1 to 3.0 & 0.72 & 0.82 \\
\hline $7.0-8.9$ & -0.8 to 2.7 & 0.49 & 0.66 & -0.8 to 2.6 & 0.50 & 0.60 \\
\hline $9.0-10.9$ & -1.5 to 2.8 & 0.65 & 0.92 & -1.8 to 3.8 & 0.60 & 1.00 \\
\hline $11.0-12.9$ & -1.4 to 2.8 & $0.51 *$ & 0.93 & -1.1 to 3.2 & $1.06^{*}$ & 1.08 \\
\hline $13.0-14.9$ & -2.4 to 2.2 & 0.31 & $1.19+$ & -1.7 to 2.3 & 0.67 & $0.86 \dagger$ \\
\hline $15.0-16.9$ & -2.8 to 0.6 & -0.49 & $0.85+$ & -1.6 to 0.8 & -0.46 & $0.57 \dagger$ \\
\hline
\end{tabular}

*Significant difference between mean values of males and females at $\mathrm{p}<0.05$.

†Significant difference between variances at $\mathrm{p}<0.05$. 
Table 4. Estimated dental age/chronological age vs sex

\begin{tabular}{lcc}
\hline & Male $(\%)$ & Female $(\%)$ \\
\hline EDA $>$ CA & 68 & 70 \\
EDA $=$ CA & 5 & 5 \\
EDA $<$ CA & 27 & 25 \\
\hline & 100 & 100 \\
\hline
\end{tabular}

$\mathrm{p}>0.05$.

$\mathrm{X}^{2}=0.42$ (2 degrees of freedom).

\section{DISCUSSION}

Accurate age data are needed in medicine and dentistry, being relevant to the timing of treatment procedures in endocrinology, pediatric dentistry and orthodontics. This information is also important in the area of forensic science, when matters of consent or criminal liability arise, or in the identification of deceased persons.

In developing countries reliable registration of birth details is often not a priority. Individuals may not have accurate information of their date of birth, or they may choose to suppress such information. In such circumstances age determination techniques, i.e., estimation of CA, may be required. ${ }^{20}$

The method of Demirjian, devised by recording the tooth development stages of children of FrenchCanadian background, has been used subsequently in a number of different populations. ${ }^{18,19,21}$ The results of our study have shown that the revised method of Demirjian $^{1}$ is not an accurate predictor of age in South Australian children.

Estimated dental age coincided with CA in only a small percentage of cases. The mean of the differences between EDA and CA was consistently outside the range of what would be considered acceptable for forensic age determination. The estimated age of some subjects was widely different from CA, with the greatest difference an over-estimation of age by 3.8 years. When a difference of \pm 0.5 year was defined as acceptable, only 34.7 per cent of males and 39.6 per cent of females fell within the category $\mathrm{EDA}=\mathrm{CA} \pm 0.5$.

In the lower age groups EDA was greater than CA significantly more often. However, there was a marked change over the age of 15 years in both males and females, when EDA tended to be less than CA. This indicates that South Australian children are less advanced in the early years compared with the Demirjian $^{1}$ standard, but more advanced once they are over 15 years of age.

Table 5. Estimated dental age/chronological age vs country of birth

\begin{tabular}{lccr}
\hline & Australian $(\%)$ & Non-Australian $(\%)$ & Total \\
\hline EDA $>$ CA & $386(70)$ & $42(68)$ & 428 \\
EDA=CA & $25(4)$ & $7(11)$ & 32 \\
EDA<CA & $142(26)$ & $13(21)$ & 155 \\
\hline & $553(100)$ & $62(100)$ & 615 \\
\hline
\end{tabular}

$\mathrm{p}>0.05$.

$\mathrm{X}^{2}=5.4$ (2 degrees of freedom).
It was demonstrated that sexual dimorphism with regard to tooth development is not marked in the earlier age groups. However, with increasing maturity, variation between the sexes increases. This is in keeping with the findings of other studies, and reaffirms that any assessment of dental maturation must take into account these gender differences.

No statistical significance was shown between children of Australian and non-Australian birth, with respect to the differences between EDA and CA. For differences between EDA and CA, there was again no statistical significance between Australian-born children with parents of Australian birth and those with one or both non-Australian parents. For children with a large discrepancy between EDA and CA (>2.5 years), no obvious relationship to country classification was discerned. This would appear to be a reflection of the multicultural nature of our society.

\section{CONCLUSIONS}

The results of our study have shown that the Demirjian $^{1}$ system has limitations when used to estimate the age of South Australian children.

Generation of new standard curves, specific to the Australian population, is indicated.

\section{ACKNOWLEDGMENTS}

This project was supported by the Australian Dental Research Foundation. Our thanks to The Board and Ethics Committee of the South Australian Dental Service, SADS dentists, in particular Dr John Diamanti and Dr David Fox, and private orthodontists in Adelaide. Our great thanks also to Mrs Wendy Schwerdt for her statistical support.

\section{REFERENCES}

1. Demirjian A, Goldstein H. New systems for dental maturity based on seven and four teeth. Ann Hum Biol 1976;3:411-421.

2. Demirjian A. Dentition. In: Faulkner F, Tanner JM, eds. Human Growth 2. London: Baillier Tindall,1978:413-444.

3. Demirjian A, Buschang PH, Tanguay R, Patterson DK. Interrelationships among measures of somatic, skeletal, dental and sexual maturity. Am J Orthod 1985;88:433-438.

4. Lewis AB, Garn SM. The relationship between tooth formation and other maturational factors. Angle Orthod 1960;30:70-77.

5. Hotz R. The relation of dental calcification to chronological and skeletal age. Proceedings of the European Orthod Soc Albani. The Hague 1959;140-149.

6. Nolla CM. The development of the permanent teeth. J Dent Child 1960;27:254-266.

7. Haaviko K. The formation and the alveolar and clinical eruption of the permanent teeth. An orthopantomographic study. Thesis. Suom. Hammaslaak Toim 1970;66:103-170.

8. Liliequist B, Lundberg M. Skeletal and tooth development. A methodological investigation. Acta Radiol 1971;11:97-111.

9. Gustafson G, Koch G. Age estimation up to 16 years of age based on dental development. Odont Revy 1974;25:297-306.

10. Nielsen HG, Ravn JJ. A radiographic study of mineralization of permanent teeth in a group of children aged 3-7 years. Scand J Dent Res 1976;84:109-118.

11. Demirjian A, Goldstein H, Tanner JM. A new system of dental age assessment. Hum Biol 1973;45:211-227. 
12. Hagg U, Matsson L. Dental maturity as an indicator of chronological age: the accuracy and precision of three methods. Eur J Orthod 1985;7:25-34.

13. Staaf V, Mornstad H, Welander U. Age estimation based on tooth development: a test of reliability and validity. Scand J Dent Res 1991;99:281-286.

14. Garn SM, Lewis AB, Koski K, Polacheck DL. The sex difference in tooth calcification. J Dent Res 1958;37:561-567.

15. Thompson GW, Anderson DL, Popovich F. Sexual dimorphism in dentition mineralization. Growth 1975;39:289-301.

16. Nystrom M, Ranta R, Kataja M, Silvola H. Comparisons of dental maturity between the rural community of Kuhmo in northeastern Finland and the city of Helsinki. Community Dent Oral Epidemiol 1988;16:215-217.

17. Harris EF, McKee JH. Tooth mineralization standards for blacks and whites from the middle southern United States. J Forensic Sci 1990;35:859-872.

18. Davis PJ, Hagg U. The accuracy and precision of the "Demirjian System" when used for age determination in Chinese children. Swed Dent J 1994;18:113-116.

19. Mornstad H, Reventlid M, Teivens A. The validity of four methods for age determination by teeth in Swedish children: a multicentre study. Swed Dent J 1995;19:121-130.
20. Voors AW. 'Can dental development be used for assessing age in underdeveloped communities?' J Trop Pediatr Environ Child Health 1973;19:242.

21. Koshy S, Tandon S. Dental age assessment: the applicability of Demirjian's method in South Indian children. Forensic Sci Int 1998;94:73-85.

22. Dahlberg G. Statistical methods for Medical and Biological students. London: George Unwin Ltd, 1940.

23. Standard Australian Classification of Countries. Australian Bureau of Statistics, 1998.

Address for correspondence/reprints:

Dr Jane Taylor

Forensic Odontology Unit

Dental School

The University of Adelaide

Adelaide, South Australia 5005

Email: elaine.formenti@adelaide.edu.au 